Nach 40 Stunden bei $160^{\circ}$ C. neutralisirte Säure 25,8 n 136 (Grenze der Einwirkung)... 26,7.

9. Krystallisirtes Thymol $74,0 \mid 1,13$ Aeq. 114 StunEssigsäure.........26,0 $\left.\left.\right|_{1,00,} ^{\mathrm{C}^{20} \mathrm{H}^{14} \mathrm{O}^{2}}\right\} \begin{gathered}\text { den bei } \\ 150^{\circ} \mathrm{C} \text {. }\end{gathered}$

Neutralisirte Säure 8 Hundertstel.

Phenol und das ihm homologe Thymol vereinigen sich direct nach Art der Alkohole mit Säuren; die Verbindungen haben ihre festen Grenzen, diese sind aber für die Phenole enger als für die Alkohole, das Verbältniss der Neutralisation ist $3 \mathrm{mal}$ so gering mit Benzoësäure, $10 \mathrm{mal}$ so gering mit Essigsäure. Die Phenole zeigen den wirklichen Alkoholen paralleles Verbalten, gehorchen jedoch andern Gesetzen. (Journ.de Pharm. et de Chim. Juin 1863.)

Dr. Reich.

\title{
Prüfung der Alkohole und Aether auf ihre Reinheit.
}

Für mit Sorgfalt durch Destillation und Austrocknen gereinigte Alkohole und Aether fehlt noch in den meisten Fällen die Controle. Berthelot kommt durch seine Untersuchungen $\mathrm{zu}$ folgenden Resultaten:

1. Ein reiner zusammengesetzter Aether muss durch ein Alkali zersetzt werden können, indem er 1 Aeq. desselben sättigt. Dieses verspricht zu einer alkalimetrischen Analyse der Aether und analoger Verbindungen zu führen, gegründet auf Anwendung einer titrirten $\mathrm{Ba}$ rytlösung.

2. Durch dieselbe Flüssigkeit kann man die Gegenwart selbst sehr kleiner Mengen zusammengesetzter Aether in einem Alkohole oder einem einfachen Aether finden. Man bringt in eine Retorte 10 C.C. titrirte Barytlösung und eine bestimmte Menge des zu untersuchenden Körpers und erhitzt 100 Stunden auf $100^{\circ} \mathrm{C}$. Ist der Alkohol rein, wie es gewöhnlich mit gewöhnlichem Alkohol der Fall ist, so wird der Barytgehalt nicht verändert. Im Amylalkohol findet man fast immer eine kleine Menge zusammengesetzter Aether, ebenso im gewöhnlichen Aether selbst nach der Digestion mit Kalkmilch.

Um die Gegenwart eines neutralen Aethers in reinem Alkohol zu erkennen, genügt es, diesen Alkohol mit dem doppelten Volumen Wasser 24 Stunden auf $150^{\circ}$ zu 
erhitzen. Der neutrale Aether geht in grosser Menge in Säure über.

3. Freie Säure in Alkohol und Aether wird leicht durch Baryt bestimmt. Ameisenäther ist stets sauer, aber seine Zersetzung geht zu schnell vor sich, als dass man die freie Säure dem Gewichte nach bestimmen könnte; bei den andern Aethern ist die Bestimmung sehr sicher.

4. Eine kleine Menge Wasser in neutralem Aether findet man, indem man diesen 20 oder 30 Stunden auf $150^{\circ}$ erhitzt. Das Wasser zerlegt fast $1 \mathrm{Aeq}$. des Aethers in Säure und Alkohol. Man bestimmt darauf die Säure durch titrirte Barytlösung. Unterwirft man mit Sorgfalt gereinigten Essigäther dieser Probe, so findet man 1/100 hartnäckig zurückgehaltenes Wasser, das ihm schwer zu entziehen ist.

3. Eine kleine Menge Wasser in Alkohol findet man, indem man diesen Alkohol mit einem völlig wasserfreien zusammengesetzten Aether mischt und 20-30 Stunden auf $150^{\circ}$ erhitzt. Ist der Alkohol wasserfrei, so darf die Mischung nicht sauer werden.

6. Die Gegenwart einer kleinen Menge Alkohol in einem neutralen Aether, z. B. im Essigäther, lässt sich erkennen durch Erhitzen dieses Aethers mit einem bestimmten Gewichte sehr reiner Essigsäure. Für den im Aether eingeschlossenen Alkohol wird der Gehalt der Säure sich vermindern. (Journ. de Pharm. et de Chim. Juillet 1863.)

Dr. Reich.

\section{Jodäthyl.}

Von allen Methoden zur Darstellung des Jodäthyls ist die zuerst von Personne gegebene die beste, welche auf der Anwendung des rothen Phosphors beruht. Rieth und Beilstein ändern zweckmässig das Verhältniss der zur Bereitung des Jodäthyls erforderlichen Ingredienzien ab und geben folgende einfache Vorschrift:

Man übergiesst in einer mit einem Kühler verbundenen Retorte 10 Theile rothen Phosphor mit 50 Theilen Allsohol von 90 Proc. und trägt in Portionen 100 Theile trocknes Jod ein. Man überlässt dann das Ganze an einem kühlen Orte 24 Stunden der Ruhe und destillirt darauf das Jodäthyl ab. Es ist jetzt nur ein ganz geringer Zusatz von Natronlauge zum Destillat nöthig, um etwa noch gelöstes Jodäthyl zu fällen und dasselbe zu- 